\title{
Negative Emotions in the Field: A Narrative Analysis of EFL Researchers' Experience
}

\author{
Adilur Rahaman \\ Lecturer, Department of English \\ School of Liberal Arts and Social Sciences \\ Independent University, Bangladesh \\ Email: adilr.1987@gmail.com \\ Shuvo Saha \\ Lecturer, BRAC Institute of Languages \\ BRAC University, Dhaka, Bangladesh \\ Email: sshuvo010@yahoo.com
}

\begin{abstract}
Through narrative analysis the present research traces the range and genesis of negative emotions that three English as Foreign Language (EFL) researchers experienced in different research sites. The method of narrative analysis helps depict and interpret the lived experiences of the researchers. This study draws on autobiographical and narrative data to illustrate how negative emotions evolve during fieldwork, a research aspect that is absent in the existing literature (Bondi, 2007). Findings suggest that the researchers experience a wide range of negative emotions namely ethical dilemma, anger, anxiety, guilt, and shame. Thus the study carries implications for establishing theoretical concepts and informing policy decisions. The theory level implication is that the researchers' negative emotions evolve through and within emotionally charged phases such as ethical dilemma, anger, anxiety, guilt, and shame. As regards policy level implication, the study reinforces the appeal of previous research works that the IRB requirements should be made flexible according to specific contexts.
\end{abstract}




\section{INTRODUCTION}

Although positivist researchers deny any nexus between emotion and fieldwork, antipositivist researchers consider emotion as an integral part of field research (Copp, 2008; Spencer, 2010). In fact, qualitative research demands both emotional and intellectual labor (Holland, 2007). Emotional labor, originally conceptualized by Hochschild (1983), is "the effort a person invests in expressing or coping with his or her emotions so as to achieve objectives pertaining to his or her work" (Nutov \& Hazzan, 2011, p. 20). Thus the emotional functioning of the researcher is intricately relevant to their cognitive actions (Holland, 2007). Increasingly, there is a recognition that the researcher's own emotions are a necessary part of investigation (Blakely, 2007; Dickson-Swift, James, Kippen, \& Liamputtong, 2009; Rager, 2005). The rationale that works behind is the researcher's emotion potentially influences and informs our understandings of the topic under investigation as well as of the data (Hubbard, Backett-Milburn, \& Kemmer, 2001). Therefore, any attempt to do scholarly research ignoring the emotional aspect of the researcher may affect the decisions regarding research design and, in the long run, research outcomes.

The emotional experience in qualitative research, specifically during fieldwork, is researched to some extent taking the participants in focus (Dickson-Swift, James, Kippen, \& Liamputtong, 2008; Hubbard et al., 2001); but there is a scarcity of literature on the emotive experiences of researchers (Bondi, 2007; Brannan, 2015; Loughran \& Mannay, 2018). Besides, the literature on research methodology, aimed at sociologists and other social scientists, categorically excludes the aspect of emotional distress that researchers face (Hubbard et al., 2001). The negative emotions remain undocumented as those entail hazards (Richardson, 2001). While recording the downbeat feelings the researchers themselves can be affected by the negativities imbued in the data (Hubbard et al., 2001). Besides, the emotional vulnerability may pose threatening and discomforting experiences for both the 
writer and the reader (Emerald \& Carpenter, 2015). However, it is essential to document the negative feelings since the failure to acknowledge and manage such emotions can influence the decisions made in the field and can potentially slow down the research process (Bashir, 2018). Therefore, from a sense of responsibility and commitment to the research fraternity, this research aims to report the negative emotions that human science researchers experience during fieldwork and draw pertinent implications.

\section{NEGATIVE EMOTIONS IN FIELDWORK}

The negative emotions that researchers experience during fieldwork range from discomfort, trauma (Hubbard et al., 2001), frustration, loneliness, sadness, boredom (Nutov \& Hazzan, 2011), guilt, fear, disgust (Dickson-Swift et al., 2009), vulnerability (Kleinman \& Copp, 1993), anger (Behar, 1996), hopelessness, helplessness (Mills \& Coleman, 1994), to ethical dilemma (Hedican, 2006). Emotions as such are triggered by various factors including negative aspects of research site, certain negative situations (Lee, 1995), and the mismatch between institutional ethics protocol and lived reality of a field (Luxardo, Colombo, \& Iglesias, 2011).

The negativities of a research site, such as awkward location, lack of security, and socio-political unrest, create a negative ambience (Sampson \& Thomas, 2003); and this gives birth to negative feelings in researchers. Davies (2010) reports such a case in which an anthropologist experienced a 'disturbing panic' when he visited a Hindu burial ground in Nepal. For the anthropologist the place was a "no-man's land between two locations" as it was unknown to him and was strikingly different from his own culture (p. 81). Warden (2013) herself experienced fear when she witnessed violence in the field during an ethnographic research on sex workers. Similarly, it was her stay at an isolated small cabin in a wild forest that aroused the feelings of imprisonment and intimidation in Levy (2016). 
The situational trigger for negative emotion refers to specific events (Lee, 1995). Usually the events are of conflict involving the researchers on one side and the participants and non-participants on the other. Harris (1997) turned angry because of such trigger when she met a hostile, uncooperative, and disrespectful woman during an ethnographic fieldwork on British Deaf people in a North West town in England. Schramm (2005) reports feelings of embarrassment and shock during fieldwork in Ghana where the participants were similarly unwelcoming and hostile. Wilkins (1993) suffered from anxiety while conducting a research on childbirth. Her anxiety emerged from the apprehension of being rejected by gatekeepers and participants.

There is also evidence of institutional ethics code contributing to negative emotion. To exemplify, during his fieldwork on Egyptian Uprising of 2011 Wackenhut (2018) had to obtain written informed consent of the participants. It was a requirement of Institutional Review Board. However, the researcher could not fulfill the requisite due to safety and security concerns of the participants. The failure to adhere to the institutional ethics code generated an ethical dilemma in Wackenhut.

Researchers experience negative feelings because of the participants and their cultural norms as well. While conducting a wartime study Wax (1957) suffered from anxiety since she could not obtain sufficient data from the uncooperative Japanese American participants. Their skepticism regarding the objective of her study aroused distress and a sense of failure in the researcher. Levy's (2016) negative emotion was rooted in her misunderstanding of a participant's gesture as intimate. However, when she realized that the participant approached her out of the 'feeling rules' of the village, her feeling of guilt intensified.

\section{METHODOLOGY OF RESEARCH}

In the present study we have used narrative data derived through autobiographical narrative (Pavlenko, 2007) and narrative interview (Ayres, 2008); our aim is to explore the negative 
emotions of three EFL researchers from Bangladesh. The participants' subjective accounts of emotion shape the research design as it is useful to generate insights and context-specific meaning of human experience (Holt, 2008). Out of the three researchers, two are the authors (Adil and Shuvo) of this paper; the other one (Akash, a pseudonym) is a $\mathrm{PhD}$ candidate at a university in London.

The temporality of the narrative data ranges from 2011 to 2018. Adil and Shuvo wrote their own narratives. Akash recounted his field experiences in a narrative interview. The audio recorded interview with Akash was later transcribed and converted into a story by the researchers (Petty, Jarvis, \& Thomas, 2018). After constructing the story of field experiences we recursively read the text till code saturation was achieved (Saunders, Sim, Kingstone, Baker, Waterfield, Bartlam, Burroughs, \& Jinks, 2018). Through this process, we obtained initial codes on negative emotions which were then merged to develop themes (Saldaña, 2009).

To ensure validity of the analysis, the researchers carried out member check (Harper \& Cole, 2012) after preparing the write-up of the discussion section. In particular, the participants verified if there was any anomaly in thematization of their emotions (e.g. anxiety, shame) in respect to the critical events (Webster \& Mertova, 2007). However, in reporting the findings we followed the method of narrative analysis (Polkinghorne, 1995). In narrative analysis human experiences are presented as a coherent story followed by a discussion section (see Tsui, 2007). We selected this method to reflect and report on the negative experiences because narrative inquiry is about meaning-making of stories of lived experience (Connelly \& Clandinin, 1990).

Ontologically the present study is based on reflexive turn in social science (Holland, 1999). Reflexivity in fieldwork refers to systematically attending to the analysis of a research 
process (Brannan, 2011). The analytic focus aids understanding of the way researchers react to emotion (Li, 2018), the way knowledge is produced (Pillow, 2003), and the implication of the relationship between researcher and participants in knowledge production (Hardy, Phillips, \& Clegg, 2001). The truth the researcher witnesses thus through reflexive practice is a co-constructed one, rather than discovered, by both the researcher and the participant(s) (Alvesson, 2003).

The critics of reflexive practice promulgate that reflection on emotion may turn into self-indulgence and egoism on the part of the researchers; and thus they may get distracted from the object of inquiry (Coffey, 1999). In addition, there is a possibility that the researchers may use reflexivity as a tool to validate their findings (Chia, 1996). However, the current research does not practice self-indulgence and egoism because we neither wrote about our emotional experience while conducting the fieldwork; nor this is an attempt to authenticate any ethnographic finding since field emotion itself is the exclusive focus of this paper. It was rather a recollection of our experience after completing the fieldwork.

\section{THE NARRATIVES}

Following are the reconstructed narratives (Petty, Jarvis, \& Thomas, 2018) of negative emotions of Adil, Akash, and Shuvo during their fieldwork. The narrative reconstruction of the participants' raw experiences was done in two stages. First, we performed the narrative emplotment (see Emden, 1998; Polkinghorne, 1988). In doing so, we identified the critical events from the participants' narratives, transformed the events into codes, and rearranged the codes for story formation. Thus, once the narrative emplotment was over we stepped into the stage of recreating the stories. Clandinin and Connelly's (2000) three dimensional model of narrative thinking guided our narrative reconstruction. In our approach, the personal, temporal, and spatial dimension of the experiences were of focus. To attend to the personal dimension, we examined the participants' negative feelings situating them in social context. 
We addressed the temporal dimension by showing the temporal sequence of the scenes/experiences and the spatial dimension by incorporating physical description of the research site (see Gleddie \& Schaefer, 2014).

\section{Akash's story \\ Prologue to accessing the site, huh}

I came back to Bangladesh in 2016 to collect data for my $\mathrm{PhD}$ dissertation. Initially, I had an ideal in my mind regarding site selection and recruitment of participants. I used to believe that unknown places were the best sites and unknown people were the best participants in field research. Ironically, my concern for safety led me to select a familiar place where I had my relatives. This eventually made me feel guilty. I thought I was not following the norm of a good field research. Nevertheless, my relatives took me to a large secondary school located at a remote village of Bangladesh. There I first met the head teacher and informed him about my purpose of collecting data. The head introduced me with the English language teachersthe potential participants of the study. The initial conversations with them were full of anxiety. I was feeling uncomfortable as the socio-economic hierarchy between me and the participants was conspicuous. To be specific, I was a teacher at a reputed university in Bangladesh as well as a $\mathrm{PhD}$ candidate in London, whereas my participants were teachers in rural school. Many of them did not have access to university education. However, to efface this socio-economic gap, I decided to purchase such clothes before the next visit which would not distinguish me from my participants. Accordingly I bought some collarless shirts and sandel (a kind of local shoe); I also bought a cheaper bag instead of a polished leather bag. I wanted to look like a regular person in the site as much as possible. Thus, I became extremely self-conscious. I was constantly thinking of my participants' psychology: how they would feel, how they would respond, if they would feel pressurized, if their reputation and face were at risk, if I was putting them in some kind of embarrassing situation. 


\section{The journey of obtaining consent documents}

According to the university ethics code, I was supposed to get written consent of the head teacher. At my university, I had to submit information sheet and consent forms for field work which was approved by the ethics committee. I did not have the authority to change it personally. If I needed to change anything, it had to be approved again. Still I made one change: I arranged group interview which I was not supposed to conduct. Communication with the ethics committee to bring this change generated panic, stress, and anxiety.

Seeking written consent from the participants (as required by the ethics committee) resulted in discomfort and embarrassment. The moment I told the participants that there was a paper to sign, I could see fear in their eyes, because the consent form contained legal jargons. I had a tough time hitting it across. When the participants were ticking the boxes in the consent form, it appeared as if they were giving me consent to interrogate them, to observe the lessons, and they were giving me access to their privacy. I told the participants to read the consent form and the information sheet. The information sheet was one and a half pages; and perhaps they did not have the patience to read. In addition, they were not familiar with such information sheet. So I had to explain the content of the information sheet. I said, "it is not a document with jurisdictional implications. It means just giving me permission to collect and use some date". I also told them that they can withdraw at any time and their privacy will be protected. Nevertheless, they filled out the consent form with confusion and hesitation which was a source of anxiety for me.

\section{Am I asking leading question?}

During the interviews I thought (as my supervisors reminded me), I should invite the participants to comment on their classroom teaching: How they planned it, what they were trying to do, and what happened. In fact, this is the prescription of the research methodology textbooks. I should not ask any direct (i.e. leading) question and I should be unbiased. The 
questions should not lead participants to particular answers. The data should come naturally. When the interviewing started, the participants talked about different things, but they were not addressing the topic I was interested in. This produced an uneasy feeling. I was not getting them to talk about the teaching principles; they were talking generally about a wide range of limitations - about teachers, teaching-learning, and education in general in Bangladesh. They were not talking about their beliefs and their practices. Therefore, sometimes I wanted to ask direct questions, but due to methodological requirements, I waited for them to come to the point. On one occasion, I wanted to ask: "I saw that you are speaking 95\% of the class. Do you think you are giving less time to the students? Do you think it is justified?" I had to hold, because it would be a leading question. The fear about asking leading question made the interview process extremely stressful.

\section{Managing the dominant participants was not easy}

Finding schedules for FGDs was difficult because everyone was busy. Managing the dominant participants in FGD was equally challenging. The first trial of FGD took place at school and I found the teachers enthusiastic to talk about their profession. Except two of the participants others did not speak much. Notably the two did not need any persuasion. Alas! They were talking randomly. They rambled on and on without stopping. I realized, they had pent up emotions and the FGD gave them the opportunity to voice their likes and dislikes, grievances and frustrations, and disappointment. Thus the first trial did not produce the desired data and aroused tension in me.

\section{"Is it really necessary to observe the class?" The reluctant participants}

Though I got permission to observe the class of a participant with the help of the head teacher, the participant did not look happy at all. He had a gloomy face and an expression that was unwelcoming. The next day I went to observe the lesson. The teacher said: "Is it really necessary to observe the class?" To comfort him I told him: "Look, I have observed 
classes and I have found out teaching approaches and I haven't seen any major differences between teachers. Don't worry". Instead of being relaxed, he asked me back: "Do you really need this data?" He was hesitant, spoke in broken sentences, and could not easily accept my presence in his class. I was feeling guilty. I wanted to observe the class. I stayed overnight in a hotel away from family, paying hotel bill. I went there braving inclement weather. It was raining insistently with thunderstorm and this person was telling me I could go to his class if I really need it! Ideally if I followed the norms, I would probably have to let him go, instead of putting myself in his class. But I had already made the investment. Therefore, I had to persuade him, wait for him in the teachers' lounge to create the impression that I was harmless. The moments were frustrating and disappointing.

\section{Adil's story}

\section{The annoyed participants}

In 2011, I conducted a field work to understand the perceptions of higher secondary level students about their English textbook. The participant students resided at a rural college hostel, located within the college premise (Author, 2011). My local guide informed me that the students will be available at the hostel in the afternoon. Therefore, I went to the research site at around 6:00 p.m. to interview the students. The first participant spontaneously remarked on the textbook, "The language of the textbook is very complex and the book is too long to complete in two years". However, the second student who I approached became angry when I requested him to comment on the English textbook. He did not agree to participate in any research that is related to the English language subject. He expressed his anguish by saying, "I failed my HSC (Higher Secondary Certificate) exam last year because of the English subject. I will not speak even a single word about this subject”. He actually considered me as one of those people who made the learning of English difficult and thus made him fail in the HSC exam. Although I requested him a few more times, he did not 
agree to participate any further in the research. I felt very sad and pissed off at this as I never thought that someone might antagonize the researcher unreasonably.

Later, in 2012 I went to Madhupur to explore the linguistic consciousness of Garo community to prepare a report for a development organization. With the help of three local guides, I obtained permission from the Garo administration and entered the site. To elicit data I prepared a survey questionnaire and approached the potential participants. I informed them that they could skip writing name and disclosing their identity on the questionnaire. Nevertheless, they dissented to take part in the survey. Therefore I arranged informal conversation, under the participants' consent, and took extensive field notes. In this way I tried to collect data from more participants. Towards the end of the data collection I met an aged Garo woman. When I approached her to interview she harshly berated all of us. Two other young women joined her and threw slangs at us. Though I constantly tried to assure them of my intention to help preserve and promote their ethnic language, besides Bangla and English, I could hear hatred echoing in their voice. This made me embarrassed although I was aware that the source of such hatred was the interethnic conflict between the Garos and the Bangalis over land and economic issues.

\section{Participants expect too much!}

The question whether the researchers are change agents or not hit my consciousness while facilitating a Focus Group Discussion at the same college in Kalihati. The FGD took place in the games room of the college hostel. It was evening. Five students participated in the FGD. I noticed, when the students were reflecting on the given prompt, they expressed their expectation regarding revising the textbook in a murmuring voice. With doubt and hope one student was asking another, "Will the book be changed?" I became anxious and helpless because I knew, in Bangladesh research findings are not taken into consideration during formulating education or curriculum policy. However, had I told the participants that the 
FGD was being conducted simply to elicit some data and that researchers are not change agents, they would not have participated in the discussion. Later during the discussion the students pointed out some problems and limitations of the textbook. They thought that researchers can influence the process of textbook modification. I felt emotionally further down as I was aware that I am not a change agent.

\section{Shuvo's story}

\section{The cost of building rapport}

Upon reaching the site to collect data for my MA dissertation (Author, 2014) I straight away went to the administrative office of a rural primary school. When I entered the administrative office at around 9 a.m., a local teacher accompanied me. It used to be the workstation of the teachers. I met some of them who did not have any class at that time. We exchanged greetings and talked about my research. After the brief interaction I started collecting data for my research. I observed classes and interviewed teachers until the school temporarily took a break for tiffin. For lunch I was invited to the teachers' lounge (the same place where I met some teachers in the morning). 10 teachers were waiting there to have lunch with me. I exchanged greetings with them and sat to eat. The foods took me aback as I saw Bheja chira (water soaked flattened rice) and Roshogolla (a type of sweetmeat) in the lunch item. I was startled not because I had distaste for these foods; it was rather my body that did not find the items resourceful. During work hours I largely depend on protein for energy which the lunch Bheja chira and Roshogolla lacked. This worried me a lot as I started thinking "How am I going to do the fieldwork in the rest of the afternoon with insufficient energy level!" Moreover, the teachers' insistence was a social pressure on me as I had to keep their request. Still, to save their face and to maintain rapport I ate the lunch; but thereafter I started feeling apprehensive. 


\section{I don't have enough data!}

After the dreadful lunch I resumed collecting data at 2:00 p.m.. I started with class observation. It was in my mind that I was allowed to collect data till 4:00 pm. So I scheduled an interview after the class at 3:00 with the teacher whose class I was observing. According to the plan, the teacher and I sat in the teachers' lounge when the class ended. Right then the head teacher of the school arrived there. She informed me that he had to leave immediately to attend an urgent meeting at Upozilla Shikkha Office (Sub-District Education Office). The head teacher assured me that I could continue collecting data during her absence. Before departing, she instructed everyone around to assist me in whatever form I needed. As the head teacher left I started interviewing the teachers. After 15 minutes the interviewee hurried me to end the session. He told me, "I have to go home and do private tutoring". I felt desolated because the data did not even begin to arise at that stage. However, I curtailed my plan and asked data inducing questions only. The interview ended in next 10 minutes and I managed to gather some data; but the haste left me completely disoriented.

\section{DISCUSSION}

Narrative inquiry does not end in telling stories (Bell, 2002). It includes both how and what of a phenomenon (Petty, Jarvis, \& Thomas, 2018). Stories from the three EFL researchers help us gain a deeper understanding of how the negative emotions are experienced (Johnson 2009). To address the what aspect of narrative inquiry, a final analysis was required. At this stage, we performed a thematic analysis (Braun \& Clarke, 2014) of the stories to interpret the meaning of experience (Kaplan-Myrth, 2007; Kim, 2016). The thematic analysis of the stories reveals that five types of negative emotions were dominant in the three researchers: ethical dilemma, anxiety, anger, guilt, and shame. 


\section{Ethical dilemma}

Ethical dilemma is the consequence of clash between ethics protocol and lived realities in the field (Okyere, 2017). Akash encountered ethical dilemma while seeking written informed consent. As a requirement of the IRB (Institutional Review Board) (Ensign, 2003; Luxardo, Colombo, \& Iglesias, 2011; Sanjari, Bahramnezhad, Fomani, Shoghi, \& Cheraghi, 2014; Thomson, Ansoms, \& Murison, 2013), Akash had to obtain signature of the participants in the consent form. However, he observed that the participants reluctantly signed the documents. He felt that he was collecting the signature going against the IRB's principle of non-coercion in the field (Klitzman, 2013) which created an ethical dilemma in him. A second source of ethical dilemma for Akash was the erratic behavior of research participants during interview. Though scheduled in advance, participants appeared reluctant to give interview. Since Akash traveled miles to take the interview, it was difficult for him to cancel the appointment. However, he was tensed feeling that he was coercive to take the interview. He could not maintain another ethics requirement while conducting the Focus Group Discussion. He had to manage the dominant participants (Nyumba, Wilson, Derrick, \& Mukherjee, 2018). The moderator role he was supposed to execute according to the norm did not work in the lived reality. In the Group Interview sessions as well he had to ask some direct questions. This put him in the dilemma whether he asked leading questions, something which is prohibited during fieldwork (Agee, 2009). Moreover, during the interview the participants were not addressing the prompts which were of Akash's focus. Therefore, he had to clarify the questions by modifying those into leading questions (Ogden \& Cornwell, 2010). The act of modifying questions breaching the research ethics protocol again put him in ethical tension.

Adil also suffered from ethical dilemma when he could not gain signature from the Garo participants in the consent form but had to continue collecting data. Since the participants declined to sign in the consent form, he felt that he could not meet the basic 
criteria of a good fieldwork — collecting evidence of participants' consent (Lazaraton, 2013). However, to enrich his data corpus Adil had to persist with data collection. Thus, the tension between what he had to do and what he actually did caused ethical predicament in Adil.

\section{Anger}

The feeling of anger in fieldwork results from the unexpected, unanticipated, and unpredictable behavior of the participants. In the narrative of the three researchers, uncongenial and whimsical behavior of the participants caused anger. In case of Adil, the abusive words of the Garo woman provoked anger, as he felt that his research topic was harmless, non-political, and beneficial to the Garo community. However, such unwelcoming attitude and consequent anger is not uncommon in field work (Arditti, Joest, Lambert-Shute, \& Walker, 2010; Levy, 2016; Holland, 2007; Stodulka, 2014). In her reflection on an ethnographic fieldwork on reproductive health in Bangladesh, Rashid (2007) reports anguish filled hostility from the respondent's husband.

Apart from the unpleasant behavior of the participants, their whimsical behavior excites anger among researchers. Feeling of anger in Shuvo and Akash was instigated by the quirky behavior of the participants. Though scheduled for a longer interview, Shuvo was forced by the interviewee to conclude the interview early. Therefore, he could not generate thick data which engendered a feeling of betrayal and annoyance. Like Shuvo, Akash was also enraged by the apathy of a participant who wanted to cancel a prescheduled classroom observation. Therefore, Down, Garrety, and Badham (2006) indicate that anger can be an inevitable legitimate human reaction during fieldwork.

Sometimes participants' lack of interest in the concerns of the researcher triggers a feeling of anger in the researcher. For instance, in a trial FGD, Akash did not get the desired data as the teacher participants were keen to talk about their grievances. This resulted in 
wastage of the researcher's time and energy and consequently produced anger in the researcher. A similar challenge is reported by Zhao (2017) who could not obtain relevant data from the participants. Anger may influence the research process in a number of ways. When the research site invokes anger, a fieldworker may doubt the significance of the research topic (Harris, 1997) and may develop antipathy against the research participants (Barrett-Fox, 2011). This can ultimately affect the decision regarding inclusion or exclusion of the collected data (Barz, 2008; Fine, 1993). After experiencing anger in the sites, Adil, Shuvo, and Akash developed a feeling of repugnance toward the participants which temporarily interrupted the flow of fieldwork. The researchers also avoided rapport building with people in the field for a few days.

\section{Anxiety}

For the researchers, anxiety generated from the apprehension of failure, uncertainty, and danger. During an FGD to understand the perception of higher secondary students about English language textbook, Adil felt anxious as the participants expected that the research will contribute to significant modifications of the textbook. Adil knew that in Bangladesh policy makers hardly consult any research document while formulating a policy (Aminuzzaman, 2015; Islam \& Rahman, 2008; Koehlmoos, Rashid, Rahman, Cravioto, \& Hanney, 2009; Roshid, Siddique, Sarkar, Mojumder, \& Begum, 2015). Therefore, he felt that his research will not bring any change to the textbook. Thus, he anticipated a failure which generated a feeling of anxiety (Coleman, 2003). To get rid of the disquieting emotion, Adil finished the FGD early, though a longer session would have produced valuable data.

Like Adil, Shuvo suffered from anxiety from an apprehension of failure (Statt, 1998). When his research participants offered him soaked rice with sweetmeat as lunch in the research site, he anticipated that after the lunch he would lack energy to collect data as the foods do not contain necessary sources of energy for him to work in the afternoon. 
Nevertheless, he had the lunch to maintain rapport with the participants, and eventually could not concentrate on data collection for half an hour. Akash also suffered from anxiety which emanated from the apprehension of danger and uncertainty (Bhatia, 2009; Matsumoto, 2009). In particular, he was concerned about his safety in the field; in addition, he was not confident that he would be able to convince teachers to participate in his study.

\section{Guilt}

Guilt refers to a feeling that arises from an activity that may be harmful to others (VandenBos, 2015). It is an excruciating emotional state as the actor wishes to revoke the wrong action. In field research, guilt emanates from the following sources: (a) a researcher may feel that she is simply mugging data from a particular site; and (b) the researcher is intruding into the life of the research subjects (Hubbard, Backett-Milburn, \& Kemmer, 2001; Johnson, 2009; Masters, 1998). Guilt is a recurrent emotion in the narrative of Akash. He considered himself as an interloper when he observed the gloomy and unwelcoming face of a teacher who reluctantly allowed him to observe the classroom teaching. As the teacher asked him if he really needed the data, he felt that he was a 'data mugger' (Masters, 1998); nevertheless, he had to continue data collection as he invested time, money, and energy to stay in the field and to obtain official permission to observe the class. To contact the research participants, Akash had to phone the participants several times which, according to Akash, was an intrusion into participants' life. In other words, Akash suffered from 'contamination complex', (Wilkins, 1993) an imaginative foreboding that he might be injurious to others. A third source of guilt for Akash ensued from his perception about ideal sampling process which includes inviting only the strangers to participate in study. As he did not invite strangers to participate in his study, he felt that he was violating the rules of established research convention, even though it is not unusual to recruit familiar participants in research (Zhao, 2017). 


\section{Shame}

Shame is an uncomfortable feeling that emerges from a self-recognition of any disgrace in one's behavior, circumstances, or action (VandenBos, 2015). There were a number of attempts in methodology literature to trace the origin of shame in fieldwork. By way of example, Pollard (2009) identified the following causes of shame among $\mathrm{PhD}$ students who conducted ethnographic fieldwork: occasional digression from the fieldwork, depression, frequently returning home, and hanging out with local people in the field. Specifically, any unproductive activity in the field was a source of shame for these fieldworkers. In their reflexive account on fieldwork emotion, Satterlund and Mallinson (2006) document how failure to access a site caused embarrassment. One researcher was denied access to site because he could not convince the gatekeeper that he was a 'legitimate' researcher with relevant credentials; the other two researchers were not granted access to the site because the gatekeeper felt that the research topic was not good.

Both Adil and Akash felt shame during their fieldwork. For Adil, the source of shame was conflicts with the potential participants. Though literature on fieldwork emphasizes rapport building (Dantec, \& Fox, 2015; Gaglio, Nelson, \& King, 2006; Glesne, 1989; Malachowski, 2015) with participants, at times the endeavor to build rapport may not be successful and researchers may experience negative emotion. In the fieldwork on HSC textbook, Adil could not build rapport with the participant in the hostel, as the research topic was related to a trauma (i.e. failure in English subject) of the participant. As he realized that he was insisting the participant to reflect on a traumatic episode of life, which goes against the principle of field research (Seedat, Pienaar, Williams, \& Stein, 2004), he felt ashamed. Another shameful event for Adil took place in Madhupur while he was conducting a fieldwork on linguistic consciousness of Garo community. As there was conflict over land issues between Garo and Bangali community at the site (Cooper, 1992; Rahman, Sarker, 
Hickey, Haque, \& Das, 2014), he was verbally attacked by the Garo women when he requested them to take part in the study. Adil felt that it was inappropriate to enter Garo community for collecting data. The root of this embarrassing feeling was conflict between the researcher and the potential participant. Like Adil, Akash's embarrassment resulted from a lack of trust or absence of rapport between researcher and the researched. Intimidated by the legal jargons, the participants reluctantly ticked the boxes in the consent form. The fearful eyes of the participants were the source of embarrassment for Akash.

Sometimes a mismatch between the objective of research (e.g. interpreting the reality) and participants' desire (i.e. changing the reality) may lead to a shameful experience (Arditti, Joest, Lamber-Shute, \& Walker, 2010). Adil encountered a shameful experience while conducting an FGD for the study on English textbook which resulted from such a mismatch. When the FGD participants requested him to take initiative to change the contents of the textbook, he could recognize himself as just a researcher, not a change agent. In Bangladesh, usually research documents are not taken into consideration during policy making process (Fattah, 2018). Adil knew that he would not be able to influence the policy makers to change English textbook (which was an expectation of the research participants), he felt embarrassed.

\section{IMPLICATIONS}

The purposes of reporting negative experience in the field are manifold. These include informing policy decisions (Sampson \& Thomas, 2003), establishing theoretical concepts (Davies, 2010), producing therapeutic effect for the self (Allan \& Arber, 2018), and offering didactic (teaching related) assistance (McGarrol, 2017). By narrating and analyzing a wide range of negative emotions - an approach which is absent in the mainstream literature (Bondi, 2007)—we made an attempt to provide a comprehensive account of negative emotion. This is a theoretical contribution to the understanding of negative emotions in fieldwork. 
The findings carry policy-related implications as well. The policy implication of the study can be understood from the IRB induced anxiety. The findings indicate that negative feelings can originate from the IRB requirements. The obligation of IRB to acquire written informed consent produces anxiety. In non-western context, attempts have been made to dissipate IRB induced negative emotions by blaming western ethical codes (Hamid, 2010). The western IRB policies are defined as too rigid, culturally inappropriate, and inapplicable to the non-western context (Roshid et al., 2015). Considering the unpredictable characteristics of different research sites, we suggest that IRB ethical requirements should be made flexible (Palmer, Fam, Smith, \& Kilham, 2014; Reeves, Peller, Goldman, \& Kitto, 2013). It is necessary for the ethical requirements to be flexible since stringent ethical guidelines generate negative emotions and interrupt research progress; thus they are counterproductive. However, further research is warranted to understand how methodological prescriptions for research and IRB recommendations generate negative emotions.

\section{CONCLUSION}

To conclude, our reading of literature on researcher emotion suggests that the detailed account of how the negative emotion evolved is missing. Researchers have mainly engaged in the documentation of their reflexive practice either through vignettes or through passing reference to their negative experiences. In doing so, they have explained what specific experiences mean and thus have overlooked the how aspect of the events (see Bondi, 2007). It deprives the readers of emotion from a comprehensive understanding of negative emotion. In this article, we have storied three researchers' experiences pertinent to negative emotions and have provided narrative analysis (Polkinghorne, 1995) of how the negative emotions emerge. Still, we feel, more narrative inquiries are required on the how dimension of negative emotion in fieldwork for a complete understating of the phenomenon. 


\section{References}

Agee, J. (2009). Developing qualitative research questions: A reflective process. International Journal of Qualitative Studies in Education, 22(4), 431-447, doi: $10.1080 / 09518390902736512$

Allan, H. T., \& Arber, A. (Eds.). (2018). Introduction. Emotions and reflexivity in health and social care field research. Cham: Palgrave Macmillan.

Alvesson, M. (2003). Beyond neopositivists, romantics, and localists: A reflexive approach to interviews in organizational research. The Academy of Management Review, 28(1), 13-33. doi:10.2307/30040687

Aminuzzaman, S. M. (2015). Dynamics of public policy: Determinants of policymaking and implementation in Bangladesh. In I. Jamil, S. M. Aminuzzaman, \& S. T. M. Haque (Eds.), Governance in South, Southeast, and East Asia: Trends, issues and challenges (pp. 211-227). Cham: Springer.

Ansoms, A. (2010). The story behind the findings: Ethical and emotional challenges of field research in conflict-prone environments. Retrieved from Research in Difficult Settings website: http://conflictfieldresearch.colgate.edu/working-papers/papers/

Arditti, J. A., Joest, K. S., Lamber-Shute, J., \& Walker, L. (2010). The role of emotions in fieldwork: A self-study of family research in a corrections setting. The Qualitative Report, 15(6), 1387-1414.

Ayres, L. (2008). Narrative interview. In L. M. Given (Ed.), The Sage encyclopedia of qualitative research methods (vol. $1 \& 2)$ (p. 545). London: Sage.

Barrett-Fox, R. (2011). Anger and compassion on the picket line: Ethnography and emotion in the study of Westboro Baptist church. Journal of Hate Studies, 9(11), 11-32.

Barz, G. F. (2008). Confronting the field (note) in and out of the field: Music, voices, texts, and experiences in dialogue. In G. Barz \& T. J. Cooley (Eds.), Shadows in the field: 
New perspectives for fieldwork in ethnomusicology ( $2^{\text {nd }}$ ed.). (pp. 206-223). New York: Oxford University Press.

Bashir, N. (2018). Doing research in peoples' homes: Fieldwork, ethics and safety - on the practical challenges of researching and representing life on the margins. Qualitative Research, 18(6), 638-653. doi: 10.1177/1468794117731808

Behar, R. (1996). The vulnerable observer: Anthropology that breaks your heart. Boston, MA: Beacon Press.

Bell, J. S. (2002). Narrative inquiry: More than just telling stories. TESOL Quarterly, 36(2), 207-213. doi:10.2307/3588331

Bhatia, M. S. (2009). Dictionary of psychology and allied sciences. New Delhi: New Age International Publishers.

Bondi, L. (2007). The place of emotions in research: From partitioning emotion and reason to the emotional dynamics of research relationships. In J. Davidson, L. Bondi, \& M. Smith (Eds.), Emotional geographies (pp. 231-246). Hampshire: Ashgate.

Brannan, M. J. (2011). Researching emotions and the emotions of researching: The strange case of Alexithymia in reflexive research. International Journal of Work Organisation and Emotion, 4(3/4), 322-339. doi:10.1504/ijwoe.2011.045969

Brannan, M. J. (2015). Recognising research as an emotional journey. In C. Clarke, M. Broussine, \& L. Watts (Eds.), Researching with feeling: The emotional aspects of social and organizational research (pp. 17-34). New York: Routledge.

Chia, R. (1996). The problem of reflexivity in organizational research: Towards a postmodern science of organization. Organization, 3(1), 31-59. doi:10.1177/135050849631003

Coffey, A. (1999). The ethnographic self. Sage: London.

Coleman, A. M. (2003). Oxford dictionary of psychology. Oxford: Oxford University Press. 
Connelly, F. M., \& Clandinin, D. J. (1990). Stories of experience and narrative inquiry. Educational Researcher, 19(5), 2-14.

Cooper, J. (1992). The Garo of Bangladesh: A forest people's struggle to survive. Ethnic and Racial Studies, 15(1), 85-101. doi: 10.1080/01419870.1992.9993734

Copp, M. A. (2008). Emotions in qualitative research. In L. M. Given (Ed.), The Sage encyclopedia of qualitative research methods (volumes 1 \& 2). (pp. 249-252). London: Sage.

Davies, J. (2010). Disorientation, dissonance, and altered perception in the field. In J. Davies \& D. Spencer (Eds.), Emotions in the field: The psychology and anthropology of fieldwork experience (pp. 79-97). California: Stanford University Press.

Dickson-Swift, V., James, E., Kippen, S., \& Liamputtong, P. (2008). Risk to researchers in qualitative research on sensitive topics: Issues and strategies. Qualitative Health Research, 18, 133-144. doi:10.1177/1049732307309007

Dickson-Swift, V., James, E., Kippen, S., \& Liamputtong, P. (2009). Researching sensitive topics: Qualitative research as emotion work. Qualitative Research, 9, 61-79. doi:10.1177/1468794108098031

Down, S., Garrety, K., Badham, R. (2006). Fear and loathing in the field: Emotional dissonance and identity work in ethnographic research.M@n@gement, 9, 95-115.

Emden, C. (1998). Conducting a narrative analysis. Collegian, 5(3), 34-39.

Emerald, E., \& Carpenter, L. (2015). Vulnerability and emotions in research: Risks, dilemmas, and doubts. Qualitative Inquiry, 21(8), 741-750. doi: $10.1177 / 1077800414566688$

Ensign, J. (2003). Ethical issues in qualitative health research with homeless youths. Journal of Advanced Nursing, 43(1), 43-50. 
Fattah, K. N. (2018). Towards inclusive cities in Bangladesh: Are policies sufficient to promote inclusiveness? South Asia Journal (Special Issue), 134-141.

Fine, G. A. (1993). Ten lies of ethnography: Moral dilemmas of field research. Journal of Contemporary Ethnography, 22(3), 267-294. doi: 10.1177/089124193022003001

Gaglio, B., Nelson, C. C., \& King, D. (2006). The role of rapport: lessons learned from conducting research in a primary care setting. Qualitative Health Research, 16(5), 723-734. doi:10.1177/1049732306286695

Gleddie, D., \& Schaefer, L. (2014). Autobiographical narrative inquiry into movement and physical education: The beginning of a journey. PHEnex Journal, 6(3), 1-14.

Glesne, C. (1989) Rapport and friendship in ethnographic research. International Journal of Qualitative Studies in Education, 2(1), 45-54. doi: 10.1080/0951839890020105

Hamid, M. O. (2010). Fieldwork for language education research in rural Bangladesh: Ethical issues and dilemmas. International Journal of Research \& Method in Education, 33(3), 259-271. doi: 10.1080/1743727X.2010.511714

Hardy, C., Phillips, N., \& Clegg, S. (2001). Reflexivity in organization and management theory: A study of the production of the research 'subject'. Human Relations, 54(5), 531-560. doi:10.1177/0018726701545001

Harper, M., \& Cole, P. (2012). Member checking: Can benefits be gained similar to group therapy? The Qualitative Report, 17(2), 1-8.

Harris, J. (1997). Surviving ethnography: coping with isolation, violence, and anger. The Qualitative Report, 3(1), 1-13.

Hedican, E. J. (2006). Understanding emotional experience in fieldwork: responding to grief in a northern aboriginal village. International Journal of Qualitative Methods, 5(1), $17-24$. 
Hochschild, A. (1983). The managed heart: Commercialization of human feeling. Berkeley: University of California Press.

Holland, J. (2007). Emotions and research. International Journal of Social Research Methodology, 10(3), 195-209. doi: 10.1080/13645570701541894

Holland, R. (1999). Reflexivity. Human Relations, 52(4), 463-484. doi: $10.1177 / 001872679905200403$

Holt, N. (2008). Representation, legitimation, and autoethnography: An autoethnographic writing story. International Journal of Qualitative Methods, 2(1), 18-28.

Hubbard, G., Backett-Milburn, K., \& Kemmer, D. (2001). Working with emotion: issues for the researcher in fieldwork and teamwork. International Journal of Social Research Methodology, 4(2), 119-137.

Islam, M. S., \& Rahman, M. (2008). Challenges of policy formulation and implementation of primary education in Bangladesh: A conceptual analysis. Asian Affairs, 30(3), 40-51.

Johnson, N. (2009). The role of self and emotion within qualitative sensitive research: A reflective account. Enquire 2(2):191-214.

Kaplan-Myrth, N. (2007). Interpreting people as they interpret themselves: Narrative in medical anthropology and family medicine. Canadian Family Physician, 53(8), 12681269.

Kim, J-H. (2016). Understanding Narrative Inquiry: The crafting and analysis of stories as research. London: Sage.

Kleinman, S., \& Copp, M. (1993). Emotions and fieldwork. London: Sage.

Klitzman, R. (2013). How IRBs view and make decisions about coercion and undue influence. Journal of Medical Ethics, 39(4), 224-229. doi: 10.1136/medethics-2011 100439 
Koehlmoos, T., Rashid, M., Rahman, Z., Cravioto, A., \& Hanney, S. (2009). Understanding the role of evidence in policy making in Bangladesh (Report No. 1). Dhaka: ICDDR,B.

Lazaraton, A. (2013). Ethics in Qualitative Research. In C. A. Chapelle (Ed.), The encyclopedia of applied linguistics (pp. 1-5). Blackwell Publishing Ltd. doi: 10.1002/9781405198431.wbeal1410

Le Dantec, C. A., \& Fox, S. (2015). Strangers at the gate: Gaining access, building rapport, and co-constructing community-based research. Proceedings of the 18th ACM Conference on Computer Supported Cooperative Work \& Social Computing-CSCW. doi:10.1145/2675133.2675147

Levy, N. (2016). Emotional landscapes; discomfort in the field. Qualitative Research Journal,16(1), 39-50. doi: 10.1108/QRJ-08-2014-0036

Li, S. (2018). The natural history of a doctoral research study: the role of a research diary and reflexivity. In H. T. Allan \& A. Arber (Eds.), Emotions and reflexivity in health and social care field research (pp. 13-38). Cham: Palgrave Macmillan.

Loughran, T., \& Mannay, D. (2018). Introduction: Why Emotion Matters. In T. Loughran \& D. Mannay (Eds.), Emotion and the researcher: Sites, subjectivities, and relationships (pp. 1-15). Bingley: Emerald Publishing Limited.

Luxardo, N., Colombo, G., \& Iglesias, G. (2011). Methodological and ethical dilemmas encountered during field research of family violence experienced by adolescent women in Buenos Aires. The Qualitative Report, 16(4), 984-1000.

Masters, H. (1998). It's a family affair on public and private accounts of HIV/AIDS. In R. S. Barbour and G. Huby (Eds.), Meddling with mythology: Aids and the social construction of knowledge (pp. 73-88). London: Routledge. 
Matsumoto, D. (Ed.). (2009). The Cambridge dictionary of psychology. New York: Cambridge University Press.

McGarrol, S. (2017). The emotional challenges of conducting in-depth research into significant health issues in health geography: Reflections on emotional labour, fieldwork and life course. Area, 49(4), 436-442. doi:10.1111/area.12347

Mills, M., \& Coleman, P. (1994). Nostalgic memories in dementia—a case study. International Journal on Ageing and Human Development, 38, 203-219.

Nutov, L., \& Hazzan, O. (2011). Feeling the doctorate: Is doctoral research that studies the emotional labor of doctoral students possible? International Journal of Doctoral Studies, 6, 19-32.

Nyumba, T. O., Wilson, K., Derrick, C. J., \& Mukherjee, N. (2018). The use of focus group discussion methodology: Insights from two decades of application in conservation. Methods in Ecology and Evolution, 9(1), 20-32. doi: 10.1111/2041-210X.12860

Ogden, J., \& Cornwell, D. (2010). The role of topic, interviewee and question in predicting rich interview data in the field of health research. Sociology of Health \& Illness, 32(7), 1059-1071. doi: 10.1111/j.1467-9566.2010.01272.x

Palmer, J., Fam, D., Smith, T., \& Kilham, S. (2014). Ethics in fieldwork: Reflections on the unexpected. The Qualitative Report, 19(28), 1-13. Retrieved from https://nsuworks.nova.edu/tqr/vol19/iss28/3

Pavlenko, A. (2007). Autobiographic narratives as data in applied linguistics. Applied Linguistics, 38(2), 163-188.

Petty, J., Jarvis, J., \& Thomas, R. (2018). Core story creation: Analysing narratives to construct stories for learning. Nurse Researcher, 25(4), 47-51. doi: 10.7748/nr.2018.e1533 
Pillow, W. (2003). Confession, catharsis, or cure? Rethinking the uses of reflexivity as methodological power in qualitative research. International Journal of Qualitative Studies in Education, 16(2), 175-196. doi:10.1080/0951839032000060635

Polkinghorne, D. E. (1988). Narrative knowing and the human sciences. Albany: State University of New York Press.

Polkinghorne, D. E. (1995). Narrative configuration in qualitative analysis. International Journal of Qualitative Studies in Education, 8(1), 5-23. doi:10.1080/0951839950080103

Pollard, A. (2009). Field of screams: difficulty and ethnographic fieldwork. Anthropology Matters, 11(2), n.p.

Rager, K. (2005). Self-care and the qualitative researcher: When collecting data can break your heart. Educational Researcher, 34, 23-27. doi:10.3102/0013189x034004023

Author. (2011, May). Systemic exclusion in higher secondary English textbooks. Paper presented at the 5th BELTA International Conference, BIAM Foundation, Dhaka.

Rahman, H. M. T., Sarker, S. K., Hickey, G. M., Haque, M. M., \& Das, N. (2014). Informal institutional responses to government interventions: lessons from Madhupur national park, Bangladesh. Environmental Management, 54(5), 1175-1189.

Rashid, S. F. (2007). Accessing married adolescent women: The realities of ethnographic research in an urban slum environment in Dhaka, Bangladesh. Field Methods, 19(4), 369-383. doi: 10.1177/1525822X07302882

Reeves, S., Peller, J., Goldman, J., \& Kitto, S. (2013). Ethnography in qualitative educational research: AMEE Guide No. 80. Medical Teacher, 35(8), 1365-1379. doi:10.3109/0142159x.2013.804977

Richardson, L. (2001). Getting personal: Writing stories. International Journal of Qualitative Studies in Education, 14, 33-38. doi:10.1080/09518390010007647 
Roshid, M. M., Siddique, M. N. A., Sarkar, M., Mojumder, F. A., \& Begum, H. A. (2015). Doing educational research in Bangladesh: challenges in applying Western research methodology. In H. Zhang, P. W. K. Chan, \& J. Kenway (Eds.), Asia as Method in Education Studies: A defiant research imagination (pp. 129-143). New York: Routledge.

Author. (2014). Interpreting the English language learning (ELL) culture of Bangladesh through Said's Orientalism: A case study of secondary English language learners (Unpublished MA dissertation). East West University, Dhaka, Bangladesh.

Saldaña, J. (2009). The coding manual for qualitative researchers. London: Sage.

Sampson, H., \& Thomas, M. (2003). Lone researchers at sea: Gender, risk and responsibility. Qualitative Research, 3(2), 165-189.

Sanjari, M., Bahramnezhad, F., Fomani, F. K., Shoghi, M., \& Cheraghi, M. A. (2014). Ethical challenges of researchers in qualitative studies: The necessity to develop a specific guideline. Journal of Medical Ethics and History of Medicine, 7(14).

Satterlund, T., \& Mallinson, C. (2006). Practical realities and emotions in field research: The experience of novice fieldworkers. Social Thought and Research, 27, 123-152. doi:10.17161/STR.1808.5217

Saunders, B., Sim, J., Kingstone, T., Baker, S., Waterfield, J., Bartlam, B., Burroughs, H., \& Jinks, C. (2018). Saturation in qualitative research: exploring its conceptualization and operationalization. Quality \& Quantity, 52(4), 1893-1907. doi:10.1007/s11135017-0574-8

Schramm, K. (2005). 'You have your own history. Keep your hands off ours!' On being rejected in the field. Social Anthropology, 13(2), 171-183. doi:

$10.1017 / \mathrm{S} 0964028205001217$ 
Seedat, S., Pienaar, W. P., Williams, D., \& Stein, D. J. (2004). Ethics of research on survivors of trauma. Current Psychiatry Reports, 6, 262-267.

Spencer, D. (2010). Emotional labour and relational observation in anthropological fieldwork. In D. Spencer \& J. Davies (Eds.), Anthropological fieldwork: A relational process (pp. 1-47). Newcastle: Cambridge Scholars Publishing.

Statt, D. A. (1998). The concise dictionary of psychology ( $3^{\text {rd }}$ ed.). New York: Routledge.

Stodulka, T. (2014). Emotion work, ethnography, and survival strategies on the streets of Yogyakarta. Medical Anthropology, 34(1), 84-97. doi:

$10.1080 / 01459740.2014 .916706$

Thomson, S., Ansoms, A., \& Murison, J. (Eds.). (2013). Emotional and ethical challenges for field research in Africa: The story behind the findings. New York: Palgrave Macmillan.

VandenBos, G. R. (Ed.). (2015). APA dictionary of psychology ( $2^{\text {nd }}$ ed.). Washington, DC: American Psychological Association.

Wackenhut, A. F. (2018). Ethical considerations and dilemmas before, during and after fieldwork in less-democratic contexts: Some reflections from post-uprising Egypt. The American Sociologist, 49(2), 242-257. doi:10.1007/s12108-017-9363-z

Warden, T. (2013). Feet of clay: confronting emotional challenges in ethnographic experience. Journal of Organizational Ethnography, 2(2), 150-172.

Wax, R. H. (1957). Twelve Years Later: An Analysis of Field Experience. American Journal of Sociology, 63 (2), 133-142.

Webster, L., \& Mertova, P. (2007). Using narrative inquiry as a research method: An introduction to using critical event narrative analysis in research on learning and teaching. London: Routledge. 
Wilkins, R. (1993). Taking it personally: A note on emotion and autobiography. Sociology, 27(1), 93-100.

Zhao, Y. (2017). Doing fieldwork the Chinese way: A returning researcher's insider/outsider status in her home town. Area, 49(2), 185-189. doi:10.1111/area.12314 